\title{
Screening of Terpene Lactones and Flavonoid Glycosides in gingko biloba Capsule by UPLC- Orbitrap High Resolution MS, with Emphasis on Isomer Differentiation
}

\author{
Haiyun Zhou ${ }^{1, *}$, Weiquan Tang ${ }^{1}$, Jin Zeng ${ }^{2}$, Chengfang Tang ${ }^{1}$ \\ ${ }^{1}$ Instrumental Analysis and Research Center, Sun Yat-sen University, Guangzhou, China \\ ${ }^{2}$ Sanya Inspection Service for Quality and Technical Supervision of Hainan Province \\ *Corresponding author: zhouhy@mail.sysu.edu.cn
}

Received June 03, 2014; Revised June 30, 2014; Accepted July 09, 2014

\begin{abstract}
In present study, a method basing on accurate mass and fragmentation pattern was designed to screen the terpene lactones and flavonoids in the methanol extract of Ginkgo biloba capsule powder. An UPLC with a hybrid linear ion trap - orbitrap mass spectrometer (UPLC-LTQ-Orbitrap Elite) was used. The chromatographic analysis of the sample was performed on a $\mathrm{C}_{18}$ column $(100 \times 2.1 \mathrm{~mm}$ ID, particle size $1.9 \mu \mathrm{m})$ with gradient elution using methanol and water with $0.10 \%$ formic acid. Mass spectrometry was performed in the negative ESI mode. By comparison the accurate mass, element composition and fragment pattern, twenty-six compounds were identified, including 5 ginkgo terpene lactones (bilobalide, ginkgolide $\mathrm{A}, \mathrm{B}, \mathrm{C}$ and $\mathrm{J}$ ) and 21 flavonoid glycosides. The major glycosides identified included: kaempferol-3-O-glu-glu-rha, kaempferol-7-O-rutinoside, isorhamnetin-3-Orutinoside, kaempferol-3-O -rha-glu, quercetin-3-O- glucoside, kaempferol-3-O-rha-glu-coumaroyl and 3'methoxymyricetin-3-O-rutinoside. The structural isomers were differentiated through the characteristic ions obtained from their MS/MS spectra. In addition, a compound 3,5,4'-trihydroxyflavone-3-O-glucoside, which was not reported in G. biloba before to our knowledge, was identified in the extract. The fragmentation pathways and characteristic product ions of flavonoid glycosides were shown and summarized for the rapid identification. The developed method was proved to be useful and precise for fast qualitative analysis of flavonoid compounds in mixture.
\end{abstract}

Keywords: gingko biloba, terpene lactones, gingko biloba glycosides, glycoside fragment ions, structure characterization, UPLC-LTQ-Orbitrap MS

Cite This Article: Haiyun Zhou, Weiquan Tang, Jin Zeng, and Chengfang Tang, "Screening of Terpene Lactones and Flavonoid Glycosides in gingko biloba Capsule by UPLC- Orbitrap High Resolution MS, with Emphasis on Isomer Differentiation.” Journal of Food and Nutrition Research, vol. 2, no. 7 (2014): 369-376. doi: 10.12691/jfnr-2-7-7.

\section{Introduction}

Ginkgo biloba (G. biloba) leaf has a long history of use in China as a traditional medicine or as a source of supplement. Terpenoids and flavonoids are the active compounds in G. biloba leaf extract, in which exhibit a wide range of biological activities including cardiovascular prevention, antioxidant and hypolipidemic effect [1]. Ginkgolides and bilobalide are unique components of $G$. biloba [2]. So far, more than 30 glycosides were isolated from $G$. biloba, and most of them are isomeric compounds with location of sugar groups at the aglycone skeleton (normally at C3 and/or C7 position) [1]. The major flavonoid aglycones found in G. biloba include quercetin, kaempferol, isorhamnetin, apigenin, and myricetin. The most common sugar groups linked to the aglycone skeleton are comprised of rhamnose and glucose [3,4,5,6].

G. biloba capsule, made from its leaf extract, is a complex mixture comprising of terpene lactones and flavonoids. According to Chinese Pharmacopoeia (Ver. 2010), ginkgolides (A, B and C), bilodalide and total flavonoid glycosides are the quality control parameters. HPLC is the recommended method. When determining the flavonoid glycosides, the extracts are hydrolyzed first, three major aglycones (quercetin, kaempferol and isorhamnetin) that are then measured. The three aglycone values are converted to give an estimate of the total amount of flavonoid glycosides. Using this method, the major constituents cannot be identified.

The chemical constituents in G. biloba extract depend on the time of year at which the leaves were harvest or on growing condition. Therefore, a clear and fast quality analysis method should be established in rapid compound identification. While undergoing the quality analysis of natural products in a mixture, it is the fact that not all the standard compounds could be obtained. In recent years, high resolution mass spectrometry combined with UPLC provides a powerful on-line technique for natural product characterization in a complex mixture $[7,8,9,10]$. Hybrid linear ion trap - Orbitrap Elite mass spectrometer (LTQ- 
Orbitrap Elite) is one of the high-resolution analyzer, which enables the recorded $\mathrm{m} / \mathrm{z}$ values of ions with accuracy up to four decimal points, and it allows achieving mass error better than $5 \mathrm{ppm}$. Together with the multistage MS data, not only the element composition but also the structural information of the analytes could be obtained. In terms of flavonoid glycosides, the aglycone type, glycosylation position and sugar pattern could be determined basing on the MS/MS product ions [11-17].

In this study, UPLC with LTQ-Orbitrap Elite was applied to screen the compositions of terpene lactones and flavonoid glycosides in G. biloba capsule. In addition, the fragmentation pathways and characteristic product ions of flavonoid glycosides were shown and summarized for the rapid identification. The data presented in this study would benefit to the quality control analysis of G. biloba products.

\section{Materials and Methods}

\subsection{Sample Preparation}

The G. biloba capsule was purchased in local drug store. $10 \mathrm{mg}$ of the capsule powder was ultrasonically extracted with $10 \mathrm{~mL}$ methanol for $10 \mathrm{~min}$. After centrifugation at $10000 \mathrm{rpm}$ for 10 minutes, the supernatant was filtered through $2 \mu \mathrm{m}$ filter before UPLC/MS analysis.

Methanol (MS grade) and formic acid (analytical grade) are commercial available. Ultra-pure water was obtained by using a Milli-Q system. Reference compounds (quercetin, kaempferol and rutinose) were obtained from the National Institute for the control of Pharmaceutical and Biological Products (Beijing, China).

\subsection{UPLC-MS Conditions}

The LC-MS experiments were carried out on a hybrid linear ion trap - orbitrap mass spectrometer (LTQ Orbitrap Elite MS) coupled with an Accelar UPLC system (Thermofisher).

The extract was separated on an Hypersil Gold $\mathrm{C}_{18}$ column $(100 \times 2.1 \mathrm{~mm}$ ID, particle size $1.9 \mu \mathrm{m})$
(Thermofisher). The column oven was maintained at $25^{\circ} \mathrm{C}$ $\left( \pm 1^{\circ} \mathrm{C}\right)$. The mobile phase consisted of a gradient elution of methanol (A) and water with $0.10 \%$ formic acid (B). The gradient program was: 10\%A (0 min), 60\% A (15min), 100\%A (30 min, lasted for 10 minutes). The flow rate was $0.2 \mathrm{~mL} / \mathrm{min}$. Aliquots of $3 \mu \mathrm{L}$ of sample extract was injected into the UPLC via the autosampler for analysis.

The eluent from the column was introduced into the LTQ Orbitrap Elite MS via heated electrospray ionization (H-ESI) interface. ESI was operated in negative mode. The following MS parameters were set: heater temperature, $250^{\circ} \mathrm{C}$; ion spray voltage, $-3.5 \mathrm{kV}$; capillary temperature, $300^{\circ} \mathrm{C}$; sheath gas $\left(\mathrm{N}_{2}\right)$ flow rate, 35 arbitrary units; auxiliary gas $\left(\mathrm{N}_{2}\right)$ flow rate, 10 arbitrary units; Helium was used as collision gas and the collision energy was set $30 \%$.

The LTQ Orbitrap was operated in parallel mode so that while the orbitrap mass analyzer was acquiring the high resolution high mass accuracy full scan mass spectrum, the LTQ was acquiring $\mathrm{MS}^{2}$ spectra in data dependent mode. The orbitrap mass resolution was set to 15,000 at $\mathrm{m} / \mathrm{z} 400$ with a scan range of 100 to $1000 \mathrm{u}$.

The Orbitrap mass was calibrated using a tuning solution (provided by the manufacture) before data acquiring. All the operations, acquisition and data processing were controlled by Xcalibur software (Ver. 2.4, Thermofisher).

\section{Results and Discussion}

Total ion chromatogram (TIC) of the sample extract is shown in Figure 1. In -ESI mode, the peaks exhibited [M$\mathrm{H}]^{-}$ion for the compounds in MS spectra. The appearance of dimmers or solvent adduct ions (for example [M$\mathrm{H}+\mathrm{HCOOH}]^{-},\left[\mathrm{M}-\mathrm{H}+\mathrm{CH}_{3} \mathrm{OH}\right]^{-}$) could further support the identification of the [M-H] ions. A total of 26 compounds were characterized. Table 1 showed the obtained values for each of the detected compounds (numbered from 1 to 26 following their retention time). As shown in Table 1, some of the compounds were isomers with identical element composition.

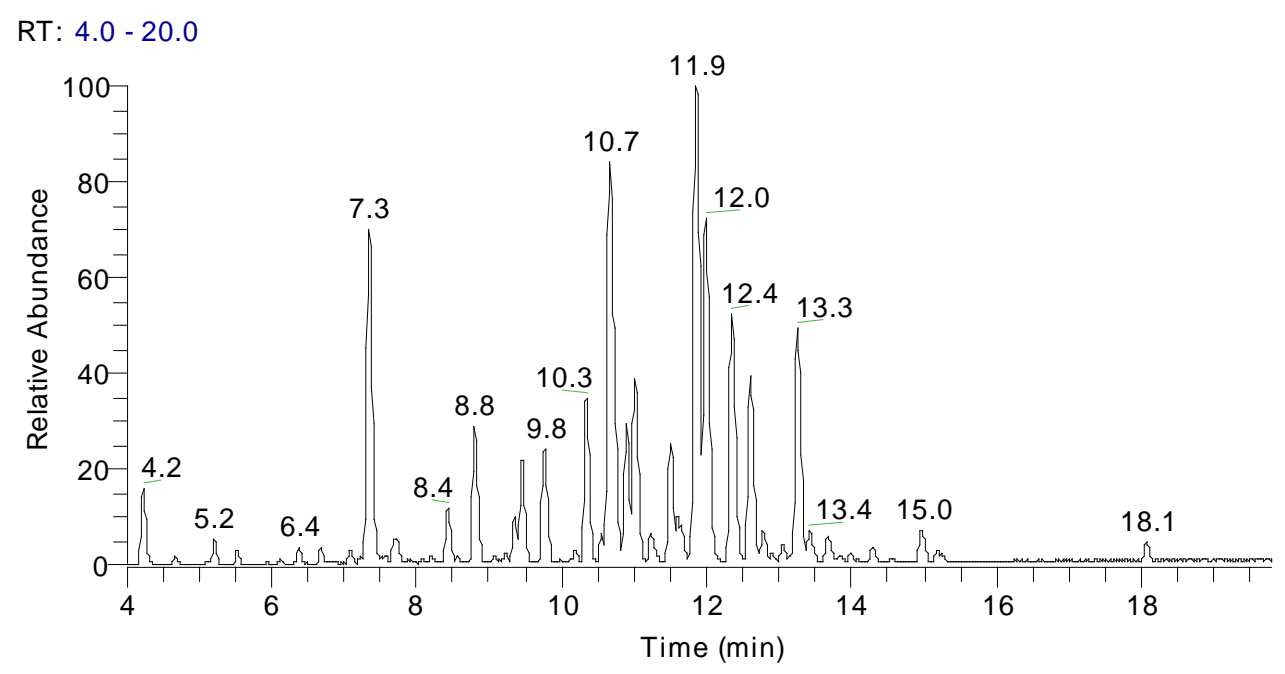

Figure 1. Full scan base peak MS chromatogram of the methanol extract of the sample. The data was acquired from Orbitrap Elite UPLC-MS spectrometer in -ESI mode 
Table 1. Chromatographic characteristics and identified ginkgo terpene lactones and flavonoid glycosides in G. bilota extract

\begin{tabular}{|c|c|c|c|c|c|}
\hline \multirow[t]{2}{*}{ No. } & \multirow[t]{2}{*}{$t_{R}(\min )$} & \multicolumn{3}{|c|}{$[\mathrm{M}-\mathrm{H}]^{-}(\mathrm{m} / \mathrm{z})$} & \multirow[t]{2}{*}{ identification } \\
\hline & & measured & error(ppm) & formula & \\
\hline \multirow{2}{*}{1} & \multirow{2}{*}{7.36} & 325.0926 & 2.44 & $\mathrm{C}_{15} \mathrm{H}_{17} \mathrm{O}_{8}$ & \multirow{2}{*}{ bilobalide } \\
\hline & & $651.1930^{\mathrm{a}}$ & 1.03 & $\mathrm{C}_{30} \mathrm{H}_{35} \mathrm{O}_{16}$ & \\
\hline 2 & 7.88 & 755.2038 & 1.16 & $\mathrm{C}_{33} \mathrm{H}_{39} \mathrm{O}_{20}$ & kaempferol-3-O-rutinoside-7-O-glucoside \\
\hline \multirow{2}{*}{3} & \multirow{2}{*}{8.47} & 423.1295 & 2.15 & $\mathrm{C}_{20} \mathrm{H}_{23} \mathrm{O}_{10}$ & \multirow{2}{*}{ ginkgolide J } \\
\hline & & $847.2668^{\mathrm{a}}$ & 1.49 & $\mathrm{C}_{40} \mathrm{H}_{47} \mathrm{O}_{20}$ & \\
\hline \multirow{2}{*}{4} & \multirow{2}{*}{8.82} & 439.1245 & 0.99 & $\mathrm{C}_{20} \mathrm{H}_{23} \mathrm{O}_{11}$ & \multirow{2}{*}{ ginkgolide C } \\
\hline & & $879.2570^{\mathrm{a}}$ & 1.61 & $\mathrm{C}_{40} \mathrm{H}_{47} \mathrm{O}_{22}$ & \\
\hline 5 & 9.36 & 625.1406 & 0.64 & $\mathrm{C}_{27} \mathrm{H}_{29} \mathrm{O}_{17}$ & myricetin-3-O-rha-glu \\
\hline 6 & 9.46 & 755.2034 & 0.59 & $\mathrm{C}_{33} \mathrm{H}_{39} \mathrm{O}_{20}$ & quercetin-3-O-glu-rha-rha \\
\hline 7 & 10.34 & 739.2089 & 0.50 & $\mathrm{C}_{33} \mathrm{H}_{39} \mathrm{O}_{19}$ & kaempferol-3-O-glu-rha-rha \\
\hline \multirow[t]{2}{*}{8} & \multirow[t]{2}{*}{10.63} & 609.1454 & 0.62 & $\mathrm{C}_{27} \mathrm{H}_{29} \mathrm{O}_{16}$ & \multirow[t]{2}{*}{ quercetin-3-O-rutinoside } \\
\hline & & 407.1346 & 2.26 & $\mathrm{C}_{20} \mathrm{H}_{23} \mathrm{O}_{9}$ & \\
\hline \multirow[t]{2}{*}{9} & \multirow[t]{2}{*}{10.7} & $453.1400^{\mathrm{b}}$ & 1.80 & $\mathrm{C}_{21} \mathrm{H}_{25} \mathrm{O}_{11}$ & \multirow[t]{2}{*}{ ginkgolide A } \\
\hline & & $815.2764^{\mathrm{a}}$ & 0.90 & $\mathrm{C}_{40} \mathrm{H}_{47} \mathrm{O}_{18}$ & \\
\hline 10 & 10.73 & 463.0877 & 1.31 & $\mathrm{C}_{21} \mathrm{H}_{19} \mathrm{O}_{12}$ & quercetin-3-O-glucoside \\
\hline 11 & 10.87 & 639.1563 & 1.05 & $\mathrm{C}_{28} \mathrm{H}_{31} \mathrm{O}_{17}$ & 3'-methoxymyricetin-3-O-rutinoside \\
\hline \multirow{2}{*}{12} & \multirow{2}{*}{11.05} & 423.1293 & 1.65 & $\mathrm{C}_{20} \mathrm{H}_{23} \mathrm{O}_{10}$ & \multirow{2}{*}{ ginkgolide B } \\
\hline & & $847.2661^{\mathrm{a}}$ & 0.63 & $\mathrm{C}_{40} \mathrm{H}_{47} \mathrm{O}_{20}$ & \\
\hline 13 & 11.26 & 463.0880 & 1.83 & $\mathrm{C}_{21} \mathrm{H}_{19} \mathrm{O}_{12}$ & quercetin-7-O-glucoside \\
\hline 14 & 11.31 & 447.0933 & 2.47 & $\mathrm{C}_{21} \mathrm{H}_{19} \mathrm{O}_{11}$ & kaempferol-7-O-glucoside \\
\hline 15 & 11.51 & 609.1459 & 1.42 & $\mathrm{C}_{27} \mathrm{H}_{29} \mathrm{O}_{16}$ & quercetin-3-O-rha-glu \\
\hline 16 & 11.66 & 431.0981 & 2.02 & $\mathrm{C}_{21} \mathrm{H}_{19} \mathrm{O}_{10}$ & 3,5,4'-trihydroxyflavone -3-O-glucoside \\
\hline 17 & 11.79 & 447.0933 & 2.47 & $\mathrm{C}_{21} \mathrm{H}_{19} \mathrm{O}_{11}$ & quercetin-3-O-rhamnoside \\
\hline 18 & 11.87 & 593.1507 & 1.01 & $\mathrm{C}_{27} \mathrm{H}_{29} \mathrm{O}_{15}$ & kaempferol-7-O-rutinoside \\
\hline 19 & 11.98 & 623.1612 & 0.85 & $\mathrm{C}_{28} \mathrm{H}_{31} \mathrm{O}_{16}$ & isorhamnetin-3-O-rutinoside \\
\hline 20 & \multirow{2}{*}{$12.37^{\mathrm{c}}$} & 755.1822 & 0.53 & $\mathrm{C}_{36} \mathrm{H}_{35} \mathrm{O}_{18}$ & quercetin-3-O-rha-glu-coumaroyl or its isomer \\
\hline 21 & & 653.1724 & 1.80 & $\mathrm{C}_{29} \mathrm{H}_{33} \mathrm{O}_{17}$ & syringetin-3-O-rutinoside \\
\hline 22 & 12.59 & 593.1509 & 1.42 & $\mathrm{C}_{27} \mathrm{H}_{29} \mathrm{O}_{15}$ & kaempferol-3-O-rha-glu \\
\hline \multirow{2}{*}{23} & \multirow{2}{*}{12.78} & 447.0930 & 1.92 & $\mathrm{C}_{21} \mathrm{H}_{19} \mathrm{O}_{11}$ & \multirow{2}{*}{ kaempferol-4'-O-glucoside } \\
\hline & & $895.1917^{\mathrm{a}}$ & -1.16 & $\mathrm{C}_{42} \mathrm{H}_{39} \mathrm{O}_{22}$ & \\
\hline 24 & 13.08 & 431.0983 & 2.37 & $\mathrm{C}_{21} \mathrm{H}_{19} \mathrm{O}_{10}$ & kaempferol-7-O-rhamnoside \\
\hline 25 & 13.26 & 739.1871 & 0.35 & $\mathrm{C}_{36} \mathrm{H}_{35} \mathrm{O}_{17}$ & kaempferol-3-O-rha-glu-coumaroyl \\
\hline 26 & 13.43 & 755.1829 & 1.49 & $\mathrm{C}_{36} \mathrm{H}_{35} \mathrm{O}_{18}$ & quercetin-3-O-rha-glu-coumaroyl or its isomer \\
\hline
\end{tabular}

RT: $4.0-20.0$
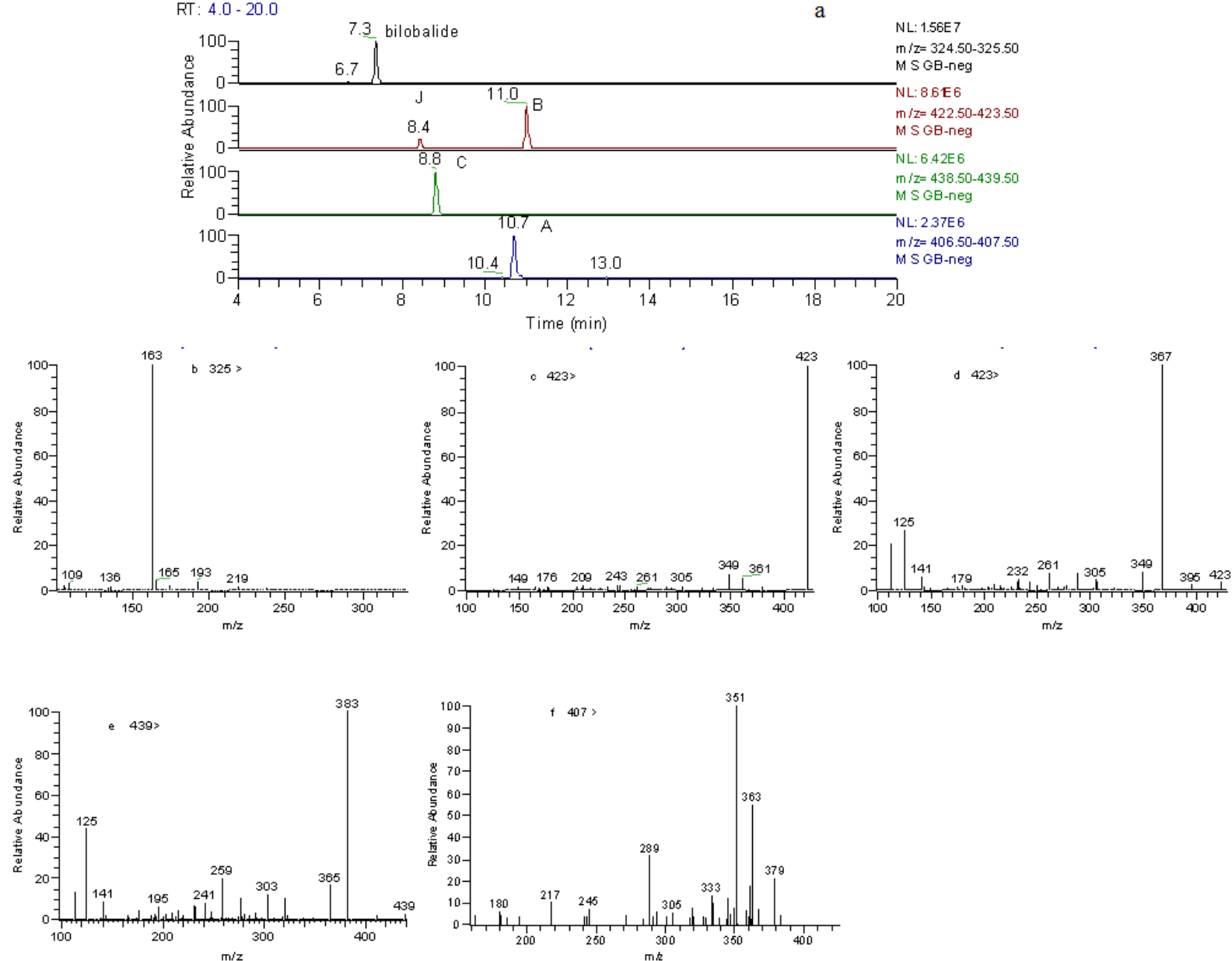

Figure 2. Extracted ion chromatogram for ginkgolides and bilobalide. Ginkgolide $\mathrm{B}$ and $\mathrm{J}$ are isomers with the identical element composition, MS ${ }^{2}$ mass spectra for bilobalide (b), ginkgolide J (c), B (d), C (e) and A (f) 


\subsection{Identification of Ginkgo Terpene Lactones $(1,3,4,9,12)$}

Ginkgolides and bilobalide are unique compounds in $G$. biloba [2]. These compounds were mainly identified basing on the data of accurate mass and chemical formulas. The extracted ion chromatogram for ginkgolides and terpene lactones was shown in Figure 2, and five peaks appeared.

Compound 1 gave a base peak at $\mathrm{m} / \mathrm{z} 325.0926$ with element composition of $\mathrm{C}_{15} \mathrm{H}_{17} \mathrm{O}_{8}$. The dimmer ion [2M$\mathrm{H}]^{-}$at $\mathrm{m} / \mathrm{z} 651.1930$ with element composition of $\mathrm{C}_{30} \mathrm{H}_{35} \mathrm{O}_{16}$ was observed. The information obtained was identical with that of bilobalide. Compound 3, 4, 9 and 12 were identified as ginkgolide $\mathrm{J}, \mathrm{C}, \mathrm{A}$, and $\mathrm{B}$, respectively, whose accurate mass and elemental composition were consistent with the corresponding compounds.

Ginkgolide $\mathrm{J}$ and $\mathrm{B}$ are isomers with different location of $-\mathrm{OH}$ groups. When using the deprotonated ion of ginkgolide $\mathrm{J}$ and $\mathrm{B}\left([\mathrm{M}-\mathrm{H}]^{-} \mathrm{m} / \mathrm{z} 423\right)$ as extracted ion, two compounds appeared (3 and 12). They yielded the same elemental composition $\mathrm{C}_{20} \mathrm{H}_{23} \mathrm{O}_{10}$ which were consistent with ginkgolide $\mathrm{J}$ and $\mathrm{B}$. According to previous studies $[10,18]$, the retention time of ginkgolide $\mathrm{J}$ on $\mathrm{C}_{18}$ column was shorter than that of ginkgolide $B$. Therefore, compound $\mathbf{3}$ was identified as ginkgolide $\mathrm{J}$ and compound 12 as ginkgolide $B$, respectively. In present study, the elution order of bilobalide and ginkgolides followed the order: bilobalide, ginkgolide J, C, A, and last ginkgolide B.

\subsection{Identification of Flavonoid Glycosides}

The elucidation procedures for flavonoid glycosides

Lots of literatures revealed that flavonoid glycosides would give a significant $[\mathrm{M}-\mathrm{H}]^{-}$ion under -ESI mode. During the MS/MS analysis, $[\mathrm{M}-\mathrm{H}]^{-}$ion would expel sugar chain to form an obvious peak of aglycone ion ( $\left.\mathrm{Y}_{0}^{-}\right)$ or radical aglycone ion $\left(\left[\mathrm{Y}_{0}-\mathrm{H}\right]^{-}\right)$(scheme 1$)$. By calculating the mass loss between the $[\mathrm{M}-\mathrm{H}]^{-}$ion and $\mathrm{Y}_{0}^{-}$ ion, the number and type of sugar residue can be differentiated. The glycosylation position could also be pointed out by comparing the abundance of $\mathrm{Y}_{0}^{-}$or $\left[\mathrm{Y}_{0}-\mathrm{H}\right]$ as well as some characteristic ions [13,14,17].

In present study, the above points would be followed when characterizing the structure of flavonoid glycosides, as well as referring to the compounds after searching the Chemspider data source. The ion fragmentation nomenclature used for flavonoid glycosides and the structures of aglycones reported in G. biloba are shown in scheme 1 .

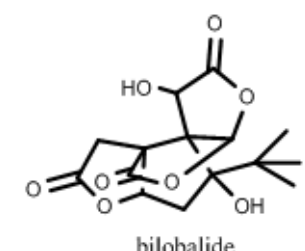

bilobalide<smiles>O=c1c(O)c(-c2ccc(O)c(O)c2)oc2cc(O)cc(O)c12</smiles>
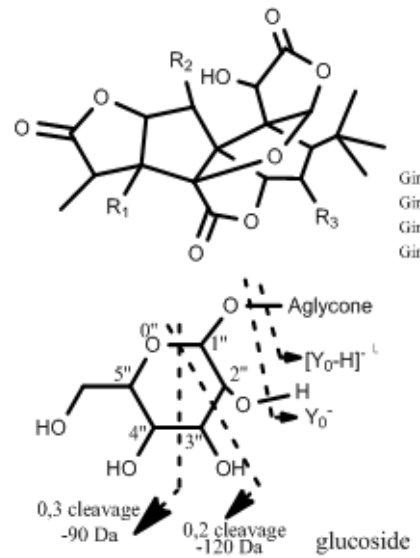

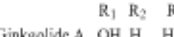
Ginkgatide $\mathrm{C}$ OH OH OH Ginkgolide $\mathrm{J}$ OH $\mathrm{H} \mathrm{OH}$<smiles>O=c1c(O)c(-c2ccc(O)cc2)oc2cc(O)cc(O)c12</smiles><smiles>COc1cc(-c2oc3cc(O)cc(O)c3c(=O)c2O)ccc1O</smiles><smiles>O=c1c(O)c(-c2cc(O)c(O)c(O)c2)oc2cc(O)cc(O)c12</smiles><smiles>COc1cc(-c2oc3cc(O)cc(O)c3c(=O)c2O)ccc1O</smiles><smiles>COc1cc(-c2oc3cc(O)cc(O)c3c(=O)c2O)cc(OC)c1O</smiles>

Scheme 1. Ion fragmentation nomenclature used for flavonoid glycosides, and structures of flavonoid aglycones, ginkgolides and bilobalide reported in G. biloba

\section{mono-glycosides $(10,13,14,16,17,23,24)$}

A total of 7 monoglycosides were identified. As mentioned before, aglycone moiety, sugar group and the glycosylation position could be distinguished from their MS/MS spectra. A typical fragmentation process, loss of sugar chain from $[\mathrm{M}-\mathrm{H}]$, was clearly observed as shown in Figure 3.

Compound 10, 13, 17 and 24 were identified as quercetin-3-O-glucoside, quercetin-7-O- glucoside, quercetin-3-O-rhamnoside and kaempferol-7-Orhamnoside, respectively. Their MS spectra were consistent with the literature data [12,13]. Compound $\mathbf{1 0}$ and 13 were isomers with different glucosyl location on quercetin skeleton. The glucosylation position could be easily distinguished after comparing the abundance of $\mathrm{m} / \mathrm{z}$ 300 and 301. The $\left[\mathrm{Y}_{0}-\mathrm{H}\right]^{-*}$ ion of quercetin $(\mathrm{m} / \mathrm{z} 300)$ was very abundance in 3-O-glycosides.

Compoud 16 gave [M-H] $]^{-}$at $m / z 431.0981\left(\mathrm{C}_{21} \mathrm{H}_{19} \mathrm{O}_{10}\right)$. In its MS/MS spectrum, after the elimination of a glucose residue (162 $\mathrm{Da}$, glu), $\mathrm{m} / \mathrm{z} 431$ gave rise to two main product ions at $\mathrm{m} / \mathrm{z} 268\left(\left[\mathrm{Y}_{0}-\mathrm{H}\right]^{-{ }^{-}}\right)$and $269\left(\mathrm{Y}_{0}^{-}\right)$which corresponded to aglycone moiety. The abundance of radical ion $\mathrm{m} / \mathrm{z} 268$ was greater than that of $\mathrm{Y}_{0}{ }^{-}$ion $\mathrm{m} / \mathrm{z}$ 269 , suggesting that the glucosyl group located at C3 position of aglycone skeleton. Therefore, compound $\mathbf{1 6}$ belonged to the class of 3-O-glucoside. The product ion 
$m / z 269$ was correlated with trihydroxyflavone where there was a $-\mathrm{OH}$ group at $\mathrm{C} 3$ position. After searching the Chemspider data source, two possible compounds were found: 3,5,7-trihydroxyflavone and 3,5,4'trihydroxyflavone. Since 3,5,4'-trihydroxyflavone could produce $\mathrm{m} / \mathrm{z} 211$ basing on the structure, therefore compound 16 was tentatively deduced as 3,5,4'trihydroxyflavone-3-O-glucoside, and the possible fragmentation pathway was shown in Figure 3. The fragment ions at $\mathrm{m} / \mathrm{z} 341$ ([M-H-90] $]^{-}$) and 311 ([M-H$\left.120]^{-}\right)$were generated from the cross-ring cleavage of glucose moiety at 0,3 site and 0,2 site, respectively. To our knowledge, this compound was not reported from $G$. biloba extracts.

As shown in Table 1, there were three monoglycoside isomers (14, 17 and 23) showing $[\mathrm{M}-\mathrm{H}]^{-}$ion at $\mathrm{m} / \mathrm{z}$ 447.093 with identical chemical composition of $\mathrm{C}_{21} \mathrm{H}_{19} \mathrm{O}_{11}$. The MS/MS spectrum of compound 17 was significantly different from the other two isomers where $\mathrm{m} / \mathrm{z} 300$ and 301 were the main product ions (assigned as quercetin). By calculating the mass loss from $\mathrm{m} / \mathrm{z} 447$ to main product ion $\mathrm{m} / \mathrm{z}$ 301, a rhamnose residue (146 Da, rha) was found. Compound 17 was finally identified as quercetin-3-Orhamnoside and its MS/MS data was identical to the literature report [13]. The other two isomers (14 and 23) exhibited similar MS/MS spectra with common product ions at $m / z 285$ (assigned as kaempferol) and the same mass loss of $162 \mathrm{Da}$ from $[\mathrm{M}-\mathrm{H}]^{-}$. The information obtained indicated that these two compounds were isomers with different substitution of glucosyl on kaempferol. After comparing with the literature data [12], compounds 14 was proposed to be kaempferol-7-Oglucoside. Taking into account of compound 23, only one product ion $\mathrm{m} / \mathrm{z} 285$ was observed corresponding to aglycone skeleton. It could be concluded to be kaempferol-4'-O-glucoside.
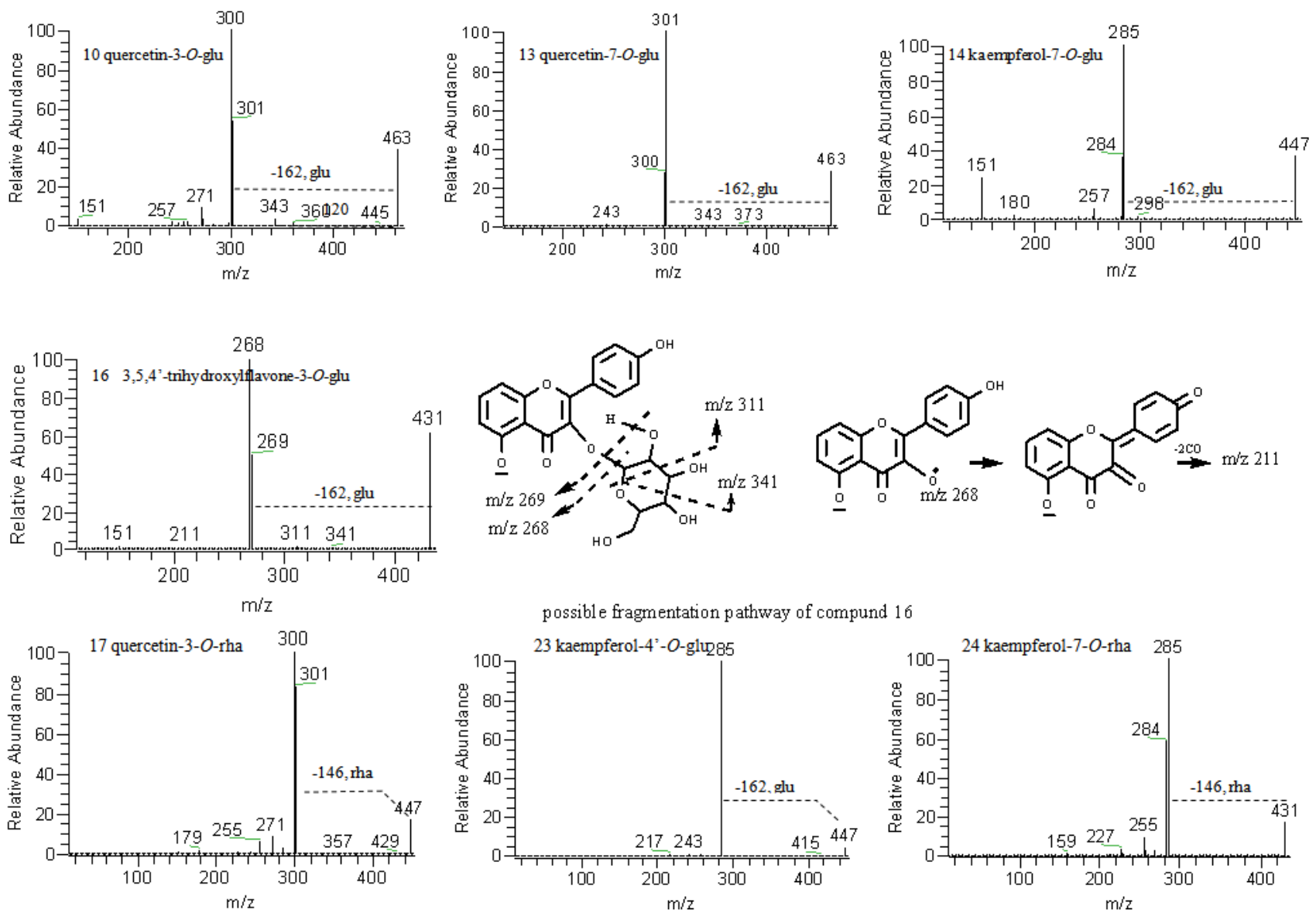

Figure 3. MS/MS spectra for monoglycosides $(10,13,14,16,17,23,24)$

Diglycosides $(5,8,11,15,18,19,21,22)$

Eight diglycosides and two groups of isomer among them were found. Their MS/MS spectra were shown in Figure 4. When deducing the structures of diglycoside, whether the two sugar residues were linked (Odiglycoside) or not (di-O-glycoside) could be distinguished by investigating the appearance of two possible losses of sugar unit and $\left[\mathrm{Y}_{0}-2 \mathrm{H}\right]^{-}$ion [12.15].

Compound 8 and 15 were isomers. They gave $[\mathrm{M}-\mathrm{H}]^{-}$ ion at $\mathrm{m} / \mathrm{z} 609.145$ and element composition of $\mathrm{C}_{27} \mathrm{H}_{29} \mathrm{O}_{16}$. In their MS/MS spectra, after a 308 Da loss (one rha unit and one glu unit), higher abundance of $\left[\mathrm{Y}_{0}-\mathrm{H}\right]^{-*}$ at $\mathrm{m} / \mathrm{z} 300$ (assigned as quercetin) was observed. It could be deduced that the sugar units were linked together and the sugar chain was located at C3 position of quercetin skeleton. Two known compounds named quercetin-3-O-rutinoside and quercetin-3-O-rha-glu, isolated from in G. biloba [19], were the possible compounds. The MS/MS spectrum of compound 8 showed a minor ion at $\mathrm{m} / \mathrm{z} 463$ (corresponding to a 146 Da loss) indicating rhamnose residue was at the terminal side of the sugar chain, and the MS/MS spectrum of compound $\mathbf{1 5}$ showed a minor ion at $\mathrm{m} / \mathrm{z} 447$ (corresponding to a 162 Da loss) indicating glucose residue was at the terminal side of the sugar chain. Therefore compound 8 was identified as quercetin-3-Orutinoside, while compound $\mathbf{1 5}$ was quercetin-3-O-rha-glu. 

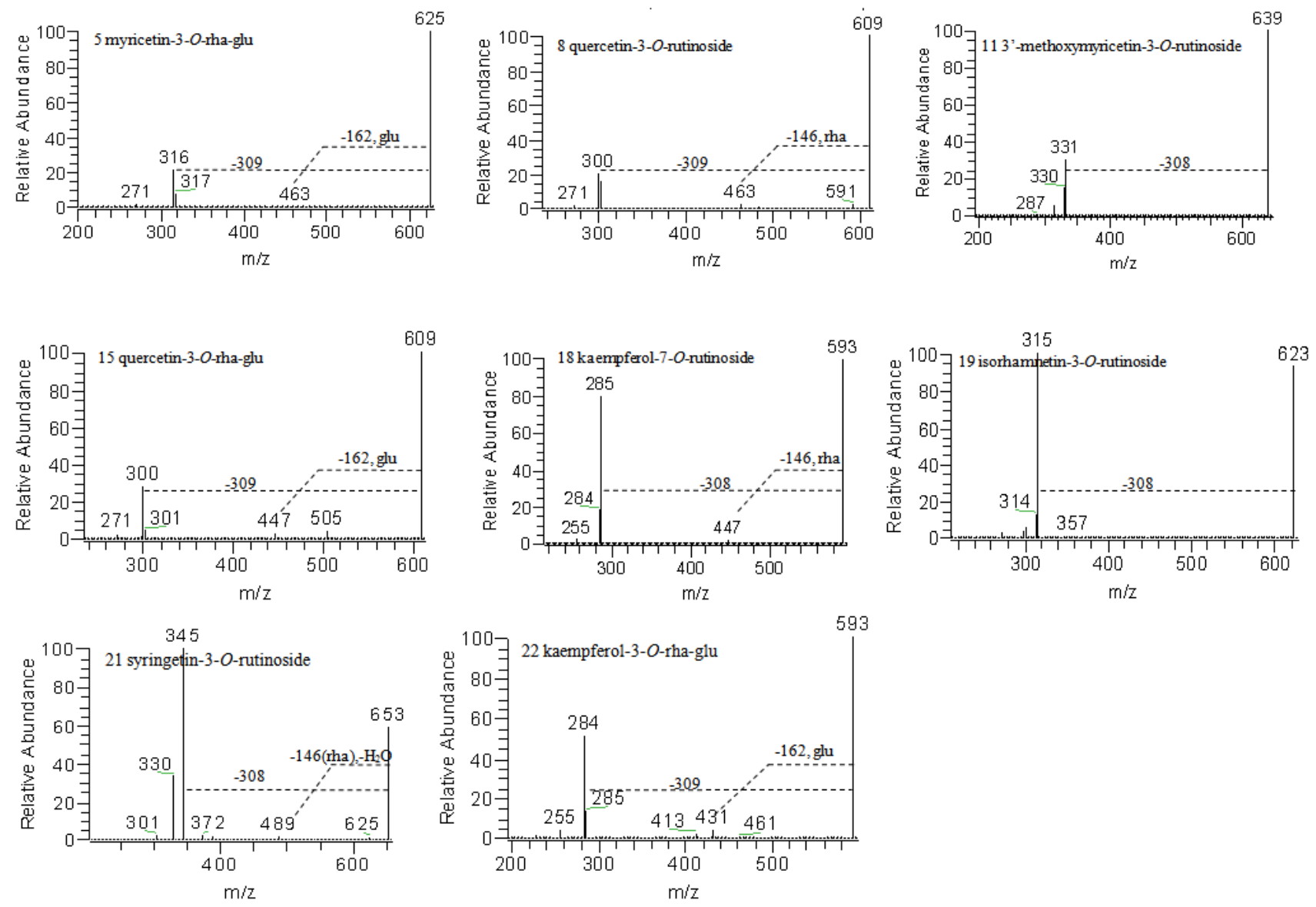

Figure 4. MS/MS spectrum for diglycosides $(5,8,11,15,18,19,21,22)$

Compound 18 and 22 were a pair of isomers with identical element composition of $\mathrm{C}_{27} \mathrm{H}_{29} \mathrm{O}_{15}$ at [M-H] $]^{-}$ion $\mathrm{m} / \mathrm{z}$ 593.150. These two compounds were found containing a rhamnose residue, a glucose residue and a kaempferol skeleton. Dissociation of $[\mathrm{M}-\mathrm{H}]^{-} \mathrm{m} / \mathrm{z} 593$ of compound 18 showed a loss of $308 \mathrm{Da}$ (corresponding to a diglycosyl group) and yielded directly major fragment ion $\mathrm{m} / \mathrm{z} 285$ (assigned as kaempferol), indicating the sugar chain was located at C7 position of kaempferol. Minor ion at $m / z 447$ (146 Da loss from $m / z$ 593, corresponding to a rhamnose residue) suggested that rhamnose group was at the terminal side of sugar chain. Therefore, compound $\mathbf{1 8}$ was identified as kaempferol-7-O-rutinoside. The MS/MS spectra of compound 22 showed a minor ion at $\mathrm{m} / \mathrm{z} 431$ (corresponding to a 162 Da loss) indicating glucose residue was at the terminal side of sugar chain. Therefore compound 22 was identified as kaempferol-3-O-rha-glu.

Compound 5, 11, 19 and 21 gave a diglycosyl loss (308 Da) yielding directly the aglycone moiety of $m / z 317,331$, 315 and 345, respectively. Compound 5, 11 and 19 were therefore tentatively characterized as compounds myricetin-3-O-rha-glu, 3'-methoxymyricetin-3-Orutinoside, isorhamnetin-3-O- rutinoside and syringetin-3$\mathrm{O}$-rutinoside, respectively. There are $-\mathrm{OCH}_{3}$ groups located in the $\mathrm{B}$ ring of aglycone skeleton for compound 11, 19 and 21, which would affect the producing of [ $\mathrm{Y}_{0^{-}}$ $\mathrm{H}]^{-*}$ in their MS/MS spectra.

Triglycosides $(2,6,7,20,25,26)$

Four peaks exhibited $[\mathrm{M}-\mathrm{H}]^{-}$ions at $\mathrm{m} / \mathrm{z}$ 755. However, their accurate masses and element composition data were not exactly identical. Compound 2 and $\mathbf{6}$ gave $\mathrm{C}_{33} \mathrm{H}_{39} \mathrm{O}_{20}$, while compound $\mathbf{2 0}$ and $\mathbf{2 6}$ gave $\mathrm{C}_{36} \mathrm{H}_{35} \mathrm{O}_{18}$, respectively.
The four peaks were classified into two groups, which represented different chemical formulas. Their MS/MS spectra were shown in Figure 5.

Compound $\mathbf{2}$ and $\mathbf{6}$ were triglycosides basing on the mass loss from precursor ion to aglycone ion. According to the MS/MS spectrum of the $[\mathrm{M}-\mathrm{H}]^{-} \mathrm{m} / \mathrm{z} 755$ of compound 2, the compound was a triglycosylated kaempferol containing a rhamnose unit and two glucose units. The spectrum showed two possible decomposition processes. First, the ion $[\mathrm{M}-\mathrm{H}]^{-} \mathrm{m} / \mathrm{z} 755$ eliminated an isolated glucose residue (162 Da) to form the major fragment ion at $m / z 593$, followed by a diglycosyl unit loss (308 Da) to yield aglycone ion $\mathrm{m} / \mathrm{z} 285$. It was therefore proposed that a glucose unit was located at C7 position of kaempferol skeleton. Second, the ion [M-H] $\mathrm{m} / \mathrm{z} 755$ also lost the diglycosyl radical (309 Da), which was proposed at C3 position, to form a radical ion $\mathrm{m} / \mathrm{z} 446$, followed by the loss of glucose unit to form $\mathrm{m} / \mathrm{z} 283$. Neutral loss of 120 Da from $\mathrm{m} / \mathrm{z} 755$ to produce $\mathrm{m} / \mathrm{z} 635$ was observed. Compound 2 was finally identified as kaempferol-3-Orutinoside-7-O-glucoside.

Compound 6 was a triglycosides of quercetin, with sugar moiety containing two rhamnose units, and a glucose unit. In its MS/MS spectrum, precursor ion $\mathrm{m} / \mathrm{z}$ 755 eliminated a triglycosyl to yield directly the aglycone moiety ion $\mathrm{m} / \mathrm{z} \quad 300$ without producing other high abundance ions, indicating the sugar units were probably linked together and located at C3 position of quercetin. A minor ion at $\mathrm{m} / \mathrm{z} 609$ (corresponding to a $146 \mathrm{Da}$ loss) indicating rhamnose residue was at the terminal side of sugar chain. The interglycosidic linkage type within the three monosacchrides could not be proposed because no 
supported data were found. The chemical formula obtained for compound $\mathbf{6}$ was consistent with a known compound named quercetin-3-O-glu-rha-rha. Compound 6 was therefore tentatively identified.
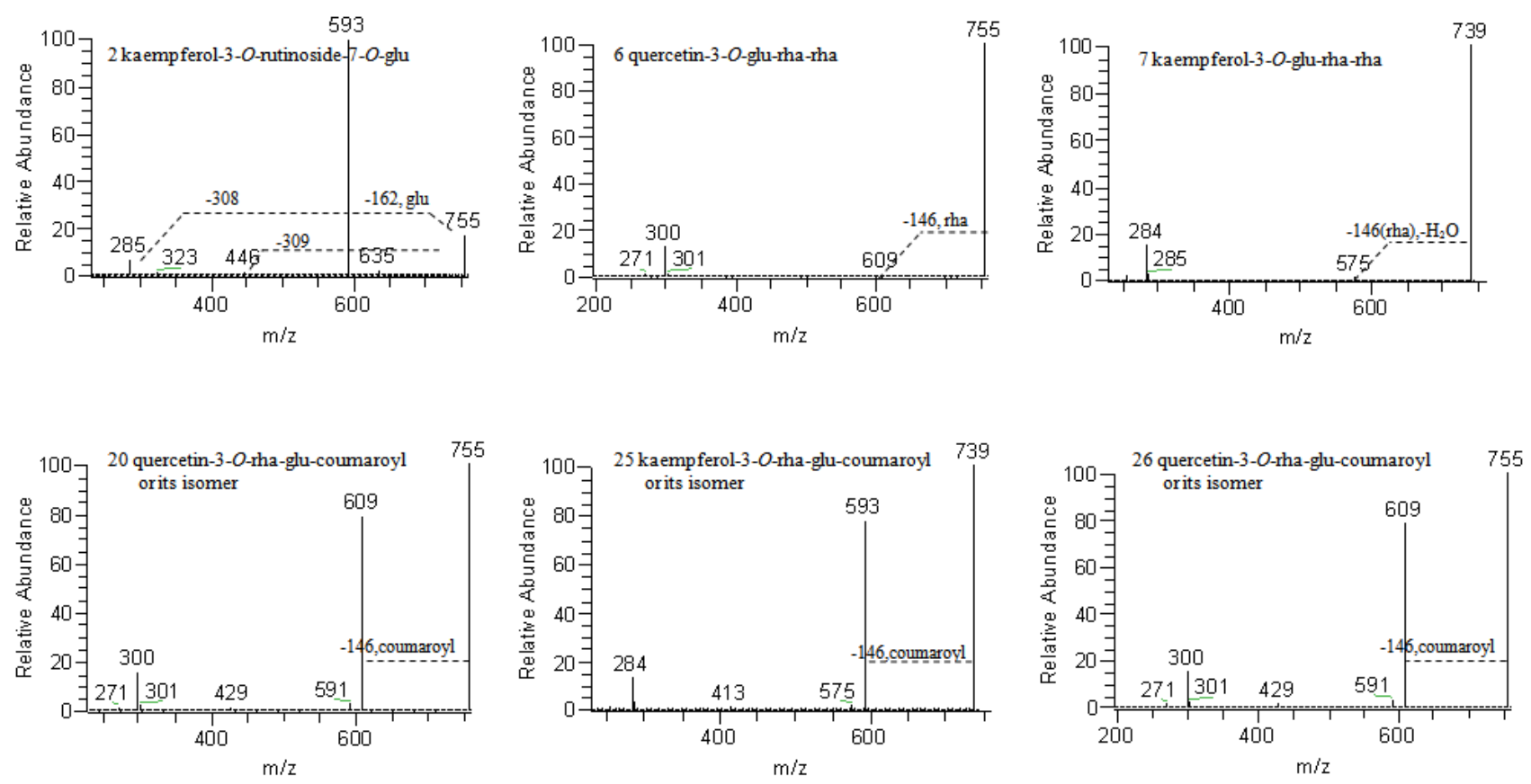

Figure 5. MS/MS spectrum for triglycosides (2, 6, 7, 20, 25, 26)

Compound 20 and $\mathbf{2 6}$ were structurally similar basing on their homological product ions in their MS/MS spectra. The presence of ions at $\mathrm{m} / \mathrm{z} 301$ and 300 suggested that these two compounds were isomers containing quercetin as aglycone skeleton. Basing on the greater abundance of $\mathrm{m} / \mathrm{z} 300$ than that of $\mathrm{m} / \mathrm{z} 301$ and the absence of $\left[\mathrm{Y}_{0}-2 \mathrm{H}\right]^{-}$ ion (the diagnostic ion of 3,7-di-O-glycosides), these compounds were proposed to be 3-O substituted glycosides. The chemical formulas obtained for these two compounds were consistent with a known compound named quercetin-3-O-rha-glu-coumaroyl, which was found in G. biloba [19]. Therefore, compound 20 and 26 were proposed as structural isomers of the above known compound. Coumaroyl group was at the terminal side of sugar chain. The interglycosidic linkage pattern within rhamnose unit and coumaroyl residue might be different between these two compounds. However, there was no supported data exhibited in the MS/MS spectra to differentiate the structures.

Two peaks $(7,25)$ were observed in the extracted ion chromatogram of $m / z$ 739. However, they showed difference between their high resolution MS data. Compound 7 gave $[\mathrm{M}-\mathrm{H}]^{-}$ion at $\mathrm{m} / \mathrm{z} 739.2089$ with $\mathrm{C}_{33} \mathrm{H}_{39} \mathrm{O}_{19}$, which was consistent with a known compound named kaempferol-3-O-glu-rha-rha found in G. biloba. Thus, peak 7 was tentatively identified.

Compound 25 gave $[\mathrm{M}-\mathrm{H}]^{-}$ion at $\mathrm{m} / \mathrm{z} 739.1876$ with $\mathrm{C}_{36} \mathrm{H}_{35} \mathrm{O}_{17}$. The chemical formula obtained from highresolution MS was consistent with a known compound named kaempferol -3-O-rha-glu-coumaroyl, which was determined in G. biloba [19]. It was therefore tentatively identified.

\section{Conclusion}

To summarize, 26 compounds including 5 ginkgo terpene lactones and 21 flavonoid glycosides were identified by the proposed high-resolution UPLC-MS method. The structural isomers were assigned according to their fragment patterns. High-resolution mass spectrometer provides a powerful technique to differentiate the chemical formulas of compounds with the same unit molecular weight. For example, there were four compounds giving $[\mathrm{M}-\mathrm{H}]^{-}$ion at $\mathrm{m} / \mathrm{z}$ 775, when using high-resolution MS, the four compounds were classified into two groups with different element composition. Full structural characterization of some of these natural compounds was impossible only on the basis of recorded MS data, but the elemental composition of the analyzed compounds permitted us to make some useful conclusion about the structures. The analytical method and data reported here could also be valuable for a better understanding of the flavonoids compounds in other plants.

\section{Funding}

This work was supported by CERS-China Equipment and Education Resources System (No. cers-1-85).

\section{References}

[1] van Beek, T.A., Ginkgo biloba. Harward Academic Publishers, Amsterdam, 2002.

[2] Jaracz, S., Malik, S. and Nakanishi, K., "Isolation of ginkgolides A, B, C, J and bilobalide from G. Biloba extracts”, Phytochem, 65, 2897-2902, 2004.

[3] Victoire, C., Haag-berruier, M., Lobstein-Guth Balz, J.P. and Anton, R., "Isolation of flavonol glycosides from Ginkgo biloba leaf", Planta Med, 54, 245-247, 1989.

[4] Vanbaelen, M. and Vanhaelen-Fastre, R., "Flavonol triglycosides from Ginkgo biloba”, Planta Med, 55, 202-204, 1989.

[5] Hasler, A., Gross, G.A., Meier, B. and Sticher, O., "Complex flavonol glycosides from leaveas of Ginkgo biloba”, Phytochem, 31, 1391-1394, 1992.

[6] Hasler, A., Stichr, O. and Meier, B., "Identification and determiantion of the flavonoids from Ginkgo biloba by high- 
performance liquid chromatography”, J Chromatogr A, 605, 41-48, 1992.

[7] Sommella, E., Pepe, G., Pagano, F.,Tenore, G.C. and Dugo, P., "Ultra high performance liquid chromatography with ion-trap TOF-MS for the fast characterization of flavonoids in Citus berganmia juice”. J Sep Sci, 36, 3351-3355, 2013.

[8] Tchoumtchoua, J., Njamen, D., Mbanya, J.C., Skaltsounis, A. and Halabalaki, M., "Structural-orientated UPLC-LTQ Orbitrap-based approach as a dereplication strategy for the identification of isoflavonoids from Amphimas pterocarpoides crude extract”, $J$ Mass Spectrom, 48, 561-575, 2013.

[9] Gai, Y.N., Chen, H., Wu, C.Y., Feng, F.,Wang, Y.X., Liu, W.Y. and Wang, S.L., "Analysis of the traditional medicine YiGan San by the fragmentation patterns of cadambine indole alkaloids using HPLC coupled with high-resolution MS”, J Sep Sci, 36, 37233732, 2013.

[10] Luo, J.L., Lu, F.L., Liu, Y.C., Shih, Y.C. and Lo, C.F., "Fingerprint analysis of Ginkgo biloba extract and Ginkgo semen in preparation by LC-Q-TOF/MS”, J Food Drug Anal, 21, 27-39, 2013.

[11] March, R.E., Miao, X.S. and Metcalfe, C.D., "A fragmentation study of a flavone triglycosides, kaemperol-3-O-robinoside-7-Orhamnoside”, Rapid Commun Mass Spectrom, 18, 931-934, 2004.

[12] Ablajan, K., Abliz, Z., Shang, X.Y., He, J.M., Zhang, R.P. and Shi, J.G., "Structural characterization of flavonol 3,7-di-O-glycosides and determination of the glycosylation position by using negative ion electronspray ionization tandem mass spectrometry", $J$ Mass Spectrom, 41, 352-360, 2006.
[13] Ablajan, K. and Tuoheti, A., "Fragmentation characteristics and isomeric differentiation of flavonol O-rhamnosides using negative ion electronspray ionization tandem mass spectrometry”, Rapid Commun Mass Spectrom, 27, 451-460, 2013.

[14] Geng, P., Sun, J.H., Zhang, R.P., He, J.M. and Abliz, Z., “An investigation of the fragmentation differences of isomers flavonalO-glycosides under different collision induced dissociation based mass spectrometry”, Rapid Commun Mass Spectrom, 23, 1519-

[15] Kerhoas, L., Aouak, D., Cingöz, A., Routaboul, J.M., Lepiniec,L., Einhorn, J. and Birlirakis, N., "Structural characterization of the major flavonoid glycosides from Arabidopsis thaliana seeds”, $J$ Agric Food Chem, 54, 6603-6612, 2006.

[16] Wojakowska, A., Perkowski, J., Góral, T. and Stobiecki, M., "Structural characterization of flavonoid glycosides from leaves of wheat (Triticum aestivum L.) using LC/MS/MS profiling of the target compounds”, J Mass Spectrom, 48, 329-339, 2013.

[17] Havttum, E. and Ekeberg., "Study of the collision-induced radical cleavage of flavonoid glycosides using negative electrospray ionization tandem quadrupole mass spectrometry”, $J$ Mass Spectrom, 38, 43-49, 2003.

[18] Ding, S., Dudley, E., Plummer, S., Tang, J., Newton, R.P. and Brenton, A.G., "Fingerprint profile of Ginkgo biloba nutrtional supplements by LC/ESI-MS/MS”, Phytochem, 69, 1555-1564, 2008.

[19] Tang, Y.P., Lou, F.C., Wang, J.H., Li, Y.F. and Zhuang, S.F., "Coumaroyl flavonol glycosides from the leaves of Ginkgo biloba", Phytochem, 58, 1251-1256, 2001. 